\title{
"Together but Separate" - What is the Correlation, If Any, between Social Loneliness, Virtual Friendship, and Use of Social Networks
}

\author{
Roman Yavich $^{1}$, Nitza Davidovitch ${ }^{1}$ \\ ${ }^{1}$ Ariel University, Ariel, Israel \\ Correspondence: Roman Yavich, Ariel University, Ariel, Israel. \\ Received: May 30, 2019 Accepted: July 16, $2019 \quad$ Online Published: July 22, 2019 \\ doi:10.11114/jets.v7i10.4395 URL: https://doi.org/10.11114/jets.v7i10.4395
}

\begin{abstract}
With the rise of online social networks, the development and maintenance of relationships are gradually being transferred to the virtual sphere. Technological developments have created a revolution that forces people to cope with situations that were unknown to them several decades ago. This study aimed to examine the association, if any, between social loneliness and virtual friendship. In addition, the effect of gender on these variables was also examined. The research participants included 313 high school students from all over Israel, with an age range of 14-18. The study examined social loneliness, the nature of virtual friendships, and participants' undue use of social networks, using two self-report scales. The research findings indicate a significant correlation between social loneliness and these variables, as well as an effect of gender. A correlation was also found between social loneliness and virtual friendships, but no interaction was found between these variables and gender, such that this research hypothesis was not confirmed. These findings might illuminate the development of interpersonal communication in the present era, as well as the role of virtual communication in the lives of individuals.
\end{abstract}

Keywords: loneliness, virtual friendship, use of social networks, friend recommendation

\section{Introduction}

"All of us together and each separately" (Yehuda Amichai); on the nature of friendship in the technological era

One of the drastic changes that occurred in the $21^{\text {st }}$ century is the rapid increase in information produced by the human species (Zahavi-Suzy, 2012). In the beginning of the previous century, information was doubled every 80 years, about 20 years ago, the growth rate diminished, and at present the information produced by the human species is being doubled every 18 months. Moreover, Zahavi-Suzy (2012) adds that the forecast is that in 20 years, the amount of information will double every 3-6 weeks.

In the second decade of the $21^{\text {st }}$ century, the web and its use are an inseparable part of the social world of children and youth (Heiman, Olnick-Shemesh \& Eden, 2014). Resler (1998) claims that the new social system is complex and requires a gradually greater exchange of information between the units that comprise it. In this way, the internet is becoming the most significant media tool. Resler (1998) adds that when speaking about technological changes that have affected our world, these can be divided into two main categories:

1. Innovative technologies that contributed to human well-being.

2. Technologies that indirectly led to sociocultural change.

The extensive introduction of digital media technologies has led, in recent years, to the growing phenomenon of virtual friendships (Aharon, Chajut \& Eshet-Alkalai, 2012).

The two key concepts in the current study are virtual friendship and social loneliness.

"Virtual friendship" - This concept is defined as friendship of which a considerable part does not take place face-to-face, and which is formed as a by-product of contemporary communication technologies (such as electronic mail, cell phones, Skype, and chats). This type of friendship has been gradually spreading among both the young and adults, and it offers a (full or partial) alternative to traditional face-to-face friendships (Boase \& Wellman, 2005; Mesch \& Talmud, 2006; Bonebrake, 2002, cited by Aharon et al., 2012). In addition, virtual friendship was defined by Hartz Soraker (2012) as 
friendship that is often formed and maintained exclusively by mediated communication, i.e., the internet. At times, this type of friendship, which takes place online, includes no real life interactions. Friendships in the virtual world are usually formed and maintained completely within the virtual world (for instance, blogs), in contrast to friendships on social networks, which are often formed and maintained outside the social networks as well (Hartz Soraker, 2012; Liao, Chen, \& Liu, 2015).

The extent of various uses of social networks among teens - According to Peter, Valkenburg and Fluckiger (2009), present-day young people were born into a reality that included an online and interactive social environment, and therefore the various uses of computers and the internet are not foreign to them, and neither is normative interpersonal interaction mediated by technological means. For this reason, it is no surprise that adolescents consume internet services at the highest rate compared to other age groups (Boniel-Nissim \& Dolev-Cohen, 2013). As of 2011, studies conducted in the US and Europe found that $60-75 \%$ of children aged 9 and older use social networks, and their rate reaches over $80 \%$ in late adolescence. In Israel, according to a survey conducted by the Sarid Institute, $72 \%$ of 8 -year-olds have smartphones and access various social networks (Rosenberg, 2015). This trend is enhanced in adolescence, as evident from the study by Weissblei (2011), showing that among the Jewish population in Israel, 91\% of teens who surf the web access social networks. Rosenberg (2015) shows that the primary use of computers is to connect to Facebook and other social networks, where $69 \%$ of female teenagers and $63 \%$ of male teenagers in Israel use personal computers for this purpose. In a focused comparison between the social networks and text apps preferred by teens, it is apparent that $80 \%$ of those aged 13-17 are active on the WhatsApp social network (a text and voice-messaging platform) and report that it is the most popular channel of communication.

The effects of virtual friendship - Studies on the different effects of virtual friendship show that young people with a low self-image create more friendships on social networks than those with a high self-image. These young people feel protected in the virtual environment and they appear to utilize the on-line anonymity and invisibility to compensate for their conspicuous limitations with regard to communication and interpersonal relations (Amichai-Hamburger, 2005; Mckenna, Green \& Greason, 2002, cited by Boniel-Nissim \& Dolev-Cohen, 2013). Side by side with the role of the internet as a source of assistance for learning, growth, emotional maturation, acquiring skills, and positive experiences, it may also be a source of negative influence and risky behaviors. Violence on the web might have a negative social or emotional impact on those involved in it (Heiman et al., 2014). Moreover, Sharabi (2013) claims that considerable use of the internet is related to few social ties and social isolation (Kraut et al., 1998, 2002).

"Loneliness" - This concept indicates a subjective feeling that is affected by life experiences, variables, and situational conditions. Social loneliness is described by various researchers as an unpleasant emotional experience (Sharabi, 2013; Sharabi \& Malka, 2011). According to Margalit (2010), social loneliness is a sensation that reflects ongoing sadness and a negative experience of the individual in a social environment. This perception is characterized by dissatisfaction with social ties or ongoing frustration with these ties (cited by Heiman et al., 2014). In addition, Perlman and Peplau (1981) showed that social loneliness refers to an unpleasant experience that occurs when one's social relationship is affected in some way. Peplau, Russell and Heim (1979) indicated that social loneliness is not necessarily the result of social isolation, rather one's cognitive evaluation of the quality or quantity of his social interactions (cited by Liu, Liu \& Wei, 2014). Moreover, Kostelecky and Lempers (1998), Marcoen and Goossens (1993), and Perlan (1988) claimed that social loneliness is a relatively common experience among teens and it may stem from teens' experience with defining their role in the family and seeking independence (cited by Kim, Kim \& Kang, 2003).

The correlation between virtual friendship and social loneliness - It is argued that use of mobile telephones reduces the individual's sense of social loneliness, as they are used as instruments for maintaining friendship, giving the teen a sensation of being loved and popular. Fischer (1992) specifies that the effect of using a mobile telephone to access social networks can improve one's social ties and psychological well-being by reducing social loneliness, isolation, and anxiety (Liu, Liu \& Wei, 2014). However, Hu (2009) found that participants reported a rise in sense of social loneliness after being in contact online and, additionally, after using online chat services social loneliness was higher than in face-to-face communication.

Moreover, Sharabi (2013) discerned two different types of communication on the internet:

A. "General interpersonal communication" on the internet serves to maintain and further establish existing ties in everyday life.

B. "Virtual friendship" refers to contact with friends with whom communication occurs only on the internet.

General interpersonal communication was found associated with a low sense of social loneliness, while virtual friendship was found associated with a high sense of social loneliness.

It is also evident that gender has an effect on the frequency of social network use by teens and generally. Kol and 
Lev-On (2014) reported that women consistently spend more time on social media than do men. Twenge, Joiner, Rogers, \& Martin (2018) claim that there has been a rise in the number of adolescents who experience depression, as well as in suicide rates and suicide attempts, from 2010-2015. Other findings show a gender bias, and female teens were found to have a higher risk. Furthermore, another study shows that adolescents who spent more time on new media (including social networks) were more inclined to report mental health problems than their same-age peers (Twenge, 2017).

In light of the research literature reviewed above, and according to the research findings cited, our main research question was: What is the correlation, if any, between reported virtual friendship and sense of social loneliness among teens, and is gender a significant factor?

This study is based on several premises.

A. The first premise, derived from the study conducted by Sharabi (2013), is that prolonged use of the internet is related to negative psychological sensations and a high sense of social loneliness.

B. The second premise is that women spend more time on the internet than men, and therefore have a higher risk of developing depression and suicide (Twenge, 2017).

Stemming from these premises, the first research hypothesis was that a positive correlation would be found between the variable of social loneliness and excessive use of social networks, such that research participants who reported a high level of social loneliness would score high on a scale measuring excess use of social networks.

The second research hypothesis was that an interaction would be found between the variable of social loneliness and the variable of gender such that, among females, social loneliness would be higher the higher their mean score on a scale measuring excess use of social networks, while among males no correlation would be found between these variables.

The third research hypothesis was that a positive correlation would be found between the variable of social loneliness and the variable of virtual friendship, such that research participants who scored high for social loneliness would also score higher for virtual friendship.

\section{Method}

\subsection{Research Design}

The dependent variable in the study is virtual friendship, and it was examined by mean scores for items on a scale measuring virtual friendship and use of social networks. The first independent variable is social loneliness, and it was measured on a scale of 1-4. The second independent variable is gender. In this study, we used a Pearson's correlation test.

\subsection{Respondents}

The study included 313 respondents, $238(76 \%)$ females and $75(24 \%)$ males. Of these, $73(23.3 \%)$ were in the $9^{\text {th }}$ grade, $63(20.1 \%)$ in the $10^{\text {th }}$ grade, $83(26.5 \%)$ in the $11^{\text {th }}$ grade, and $94(30 \%)$ in the $12^{\text {th }}$ grade. The distribution of religiosity was: $5(1.6 \%)$ defined themselves as ultra-Orthodox, $250(80 \%)$ as religious, $15(4.8 \%)$ as traditional, $32(10.2 \%)$ as secular, and $11(3.5 \%)$ as having some other religious definition.

\subsection{Instruments}

1. Informed consent form - In order to meet the ethical principles for research in humans, the respondents were told that their privacy would be maintained and that they could withdraw from the study at any time. Moreover, the nature of the study was clarified to the respondents before commencing participation.

2. Demographic questionnaire - The questionnaire included demographic data such as gender, name of school, class, town of residence, and religiosity. Inclusion criteria were Hebrew as a first language or on first language level, and age of 14-18. The purpose of the questionnaire was to rule out demographic differences between the research groups

3. Scale measuring virtual friendship and use of social networks - This scale has two parts. The first part - This part examined the nature of social networks and their features, for instance: "On which social networks are you active?". In addition, it included 40 questions that examine undue use of social networks. For instance: "I remain on the social network more than I had planned to". The respondents ranked these statements on a scale ranging from 1 (strongly disagree) to 5 (strongly agree). The reliability of the questionnaire in this study was $\alpha=0.91$. The second part of the scale was developed by Dr. Adi Sharabi (2013) and it included 13 items related to different uses of computers. Two of these items related specifically to contact with virtual friends: One question examined the existence and frequency of this contact: "To what degree do you speak with friends that you met only on social networks?" and the second examined the nature of the contact: "How important and significant is this relationship for you?". The current study used only the questions that examine the nature of the contact and their reliability was $\alpha=0.66$ (Appendix A).

4. The Revised UCLA Loneliness Scale - A self-report scale developed by Russell, Peplau and Cutrona (1980), whose 
purpose is to evaluate social loneliness. The questionnaire was translated into Hebrew by Hochdorf (1989). In our study, we used this translation, which includes 19 items. These items include sentences such as: "I am miserable because I'm so isolated from friends". The respondents ranked these statements on a scale ranging from 1 (never) to 4 (often). The scale includes reverse items, and these are numbers $12,16,17,21,26,27,30$, and 31 . The reliability of the scale in the original study was $\alpha=0.80$ (Russell, Peplau \& Cutrona, 1980). The reliability of the scale in the current study was $\alpha=0.89$ (Appendix B).

\subsection{Research Questions}

1. What correlation, if any, will be found between the scores on the loneliness questionnaire and on the questionnaire on attitudes to excessive use of social networks?

2. What interaction, if any, will be found between loneliness and the gender variable?

3. What correlation, if any, will be found between scores on the loneliness questionnaire and on the virtual friendship questionnaire?

4. What interaction, if any, will be found between the variables of social loneliness and of gender with regard to virtual friendship?

\subsection{Procedure}

At first, each of the respondents was asked to sign an informed consent form, which included an explanation of the study. The research questionnaires were not administered without this confirmation. After giving their consent, the participants completed a demographic questionnaire that included questions about their age, gender, and name of their school. Then, two questionnaires were given to the participants: a virtual friendship questionnaire and a social loneliness questionnaire. The experimental procedure took about 30 minutes. The experimenters thanked the participant; no compensation was given for participating in the study.

The respondents completed the questionnaires on a computer or smartphone. The questionnaires were sent via a link through social networks such as Facebook, electronic mail, or WhatsApp messenger. Full instructions for completing the questionnaires were given (see Appendix C) and general instructions appeared at the beginning of the link.

\section{Results}

3.1 Means and Standard Deviations of the Research Variables

Table 1. Descriptive statistics of the research variables $(\mathrm{N}=313)$

\begin{tabular}{lllll}
\hline & Gender & N & Mean & Std. Deviation \\
\hline Loneliness questionnaire & Male & 75 & 1.7547 & .50499 \\
& Female & 238 & 1.8223 & .51177 \\
Virtual friendship questionnaire & Male & 75 & 2.1480 & .59912 \\
& Female & 238 & 2.2860 & .55527
\end{tabular}

Table 1 shows that, in general, there were no significant differences in the mean scores for virtual friendship in each of the conditions, however the consistent trend is that the mean score for virtual friendship is higher among the female group than among the male group.

The following hypotheses were designed and examined according to the research questions:

A correlation will be found between scores on the social loneliness scale and on the scale measuring undue use of social networks. The analysis found that the research hypothesis was confirmed and a positive association exists between social loneliness and undue use of social networks, $(\mathrm{r}(311)=0.23, \mathrm{p}<.001)$. Namely, the higher the social loneliness the more extreme the undue use of social networks, and vice versa.

The purpose of the second research hypothesis was to examine whether there is an interaction between social loneliness and the variable of gender, such that among females a positive correlation would be found between social loneliness and their use of social networks, while among males no such correlation would be found. In order to examine the hypothesis, a Pearson's correlation test was conducted for males and females separately. The research hypothesis was confirmed, and the analysis found a positive correlation among females between reports of social loneliness and undue use of social networks $(\mathrm{r}(236)=0.24, \mathrm{p}<.001)$. In contrast, this correlation was not found among males $(\mathrm{r}(73)=0.17, \mathrm{p}>.05)$.

An association would be found between scores on the social loneliness scale and on the virtual friendship scale. The analysis found that the research hypothesis was confirmed and that there is a positive association between the social 
loneliness scale and scores on the virtual friendship scale $(\mathrm{r}(311)=0.17, \mathrm{p}<.01)$. Namely, the higher the social loneliness the higher the scores on the virtual friendship scale, and vice versa.

There is an interaction between the variable of social loneliness and the variable of gender, with regard to virtual friendship. In order to examine the hypothesis, a Pearson's correlation test was conducted for males and females separately. The research hypothesis was not confirmed and the analysis found, both among males and among females, a positive association with low power between the means on the social loneliness scale and on the virtual friendship scale.

\section{Discussion and Conclusions}

The purpose of the current study was to examine whether there is an association, and to what extent, between reported sense of social loneliness and virtual friendship among teens, and undue use of social networks. The study also examined whether gender has an impact on sense of social loneliness, while relating to variables involved in virtual friendship. The current study was initiated on the assumption that one of the main causes motivating people's use of the internet is to alleviate psychosocial problems (such as social loneliness, depression, and others). The conclusions regarding the effect of the virtual world on social loneliness are not straightforward, as some findings attest to conflicting trends. Walther (1996), Wellman and Boase (2005), and Hewiston (2003) claim that social ties formed on the web are weak by nature, since online communication lacks the basic conditions for the existence of significant friendships, such as proximity, imagination, and a variety of activities that enhance the relationship. In contrast, others claim that it is specifically the absence of identifying features in online communication that reduces the cognitive and emotional burden on participants and increases the quality of ties formed within virtual friendships (Chajut \& Eshet-Alkalai, 2012).

Confirming the first research hypothesis, a positive correlation was found between social loneliness and undue use of social networks. Namely, the higher the reported social loneliness, the higher the reports of undue use of social networks. This finding is compatible with previous findings in the literature showing that the sense of social loneliness is enhanced when social technologies are used to escape the realistic social world and to withdraw from coping with face-to-face interactions (Nowland, Necka \& Caioppo, 2017).

Confirming the second research hypothesis, among females a positive association was found between social loneliness and undue use of social networks. In contrast, among males no such association was found. These findings support those of Kol and Lev-On (2014), who found that the proportion of women who use the internet is higher than the proportion of men. Moreover, women consistently spend more time on social media than do men (Kol and Lev-On, 2014).

Rasner and Zeira (2014) show that male and female teens display different manifestations of behavior, social loneliness, and distress. Male teens express their distress outwardly while female teens express it inwardly (Kahn-Stravchinsky, Konstantinov \& Yurovich, 2005, cited in Rasner \& Zeira, 2014). Boniel-Nissim and Dolev-Cohen (2013) attest that these introverted types are those who gain the most benefit from online applications, compared to the extroverted. They feel protected in the virtual environment and appear to utilize the anonymity and invisibility to compensate for their conspicuous limitations with regard to communication and face-to-face personal relationships (Amichai-Hamburger, 2005; Mckenna, Green \& Gleason, 2002, cited by Boniel-Nissim \& Dolev-Cohen, 2013; Papadakis, 2016).

Confirming the third research hypothesis, a positive association was found between social loneliness and virtual friendship. Namely, the higher the social loneliness reported the higher the scores on the virtual friendship scale, and vice versa. This finding is compatible with previous studies, which found an association between social loneliness and use of social networks, such that people who reported high social loneliness testified to "eliminating" non-virtual relationships and preferring online relationships (Nowland, Necka \& Cacioppo, 2017).

In contrast to the fourth research hypothesis, the current study found no significant interaction between the reported social loneliness and the variable of gender with regard to virtual friendships, such that among both males and females a positive association was found between social loneliness and virtual friendships.

A possible explanation for these findings is that some $80 \%$ of the research participants identified themselves as having a religious affiliation (Jewish/ Muslim/ Christian), which might constitute a major factor since various religious affiliations might have a significant impact on people (Daniels \& Von der Ruhr, 2010; Neudörfer \& Dresdner, 2013). Religion can have a social impact (Belzer, 1976; Riley, Forer, 1968; McDonald, 1973; Moberg, 1970), expressed by granting support and counseling, i.e., in the individual's life, as well as mutual help. In addition, religious beliefs, social encounters in religious contexts, and a religious lifestyle might contribute to overcoming various problems such as social loneliness, sorrow, dissatisfaction, etc. (cited by Ronen, Zuckerman-Bareli \& Lemel, 1990). This leads to the conclusion that religious affiliation may at times impart a strong sense of communal belonging, which might reduce social loneliness and use of social networks for the purpose of maintaining social relationships. Hence, it may be 
hypothesized that the religious affiliation of most of the research participants affected the research findings.

In addition, in this study the participants were comprised of teens aged 14-18. Patchin and Hinduja (2008) offer testimonies indicating growing awareness among young people of the need to restrict the revealing of personal information on the internet (cited by Boniel-Nissim \& Dolev-Cohen, 2013). In other words, as a result of education and warnings some adolescents are careful about how they conduct themselves versus anonymous elements in order to avoid online risks. Moreover, in the current study $80 \%$ of the respondents had a religious affiliation, meaning that most had some protection on social networks. Davidovitch (2016), in her study, describes religious society as one that places special emphasis on limiting leisure consumption (for instance Internet Rimon, a restricted cellular track), for fear of a "slippery slope".

In summary, in light of the research results and due to its limitations, there is great need for further research to examine our research questions in this age range and in others. Additionally, there is need for further research to examine more extensive and diverse populations and to explore the difference between religious affiliations and the interaction with sense of social loneliness, use of social networks, and virtual friendship.

Furthermore, it seems that both males and females appeal to the help of "virtual friends" in situations of social loneliness and thus these friends help relieve social loneliness. The virtual world provides a refuge, where teens who feel lonely can find a protected and anonymous place to express themselves on social networks. However, lonely people might develop strong behavior of compulsive use of the internet on social networks, and this has negative impacts on their life (for instance, harm to other significant activities such as work, school, or significant relationships) instead of alleviating the original problems (Kim, La Rose \& Peng, 2009).

Finally, the researchers tried to bolster the existing research in this area, and to add important information regarding gender identity. It is very important to raise awareness of the possible masking of social loneliness by virtual friendships, whereby this social loneliness does not receive a proper response and may even become aggravated. Brown and Harris (1978), in their classic study of women in the community in poor parts of London, reported that women with no close relationships were defined as lonelier and thus were at a higher risk of developing depression than those who had close relationships, and that people with depression have smaller and less supportive (non-virtual) social support systems. At present, it is not yet clear how much power virtual friendship contains and therefore this topic should be further studied, as social networks are becoming an inseparable part of our lives.

\section{Acknowledgements}

The authors wish to thank Matanya Felheimer and Yifah Friedman, undergraduate students of social sciences at Ariel University, for their assistance in data collection for this study.

\section{References}

Aharon, M., Chajut, E., \& Eshet-Alkalai, Y. (2012). A comparative study of online and face-to-face friendship among Israeli school students. Open University. Chase Conference: Technology for Learning Technology Research 2010,14-10 "ע[" [Hebrew]

Boniel-Nissim, M., \& Dolev-Cohen, M. (2013). Face to face with teenagers using Facebook. Mifgash: Journal of Social-Educational Work, 38, 79-94. [Hebrew]

Brown, G. W., \& Harris, T. (1978). Social origins of depression: A reply. Psychological Medicine, s(4), 577-588. https://doi.org/10.1017/S0033291700018791

Daniels, J. P., \& Von Der Ruhr, M. (2010). Trust in others: Does religion matter?. Review of Social Economy, 68(2), 163-186. https://doi.org/10.1080/00346760902968447

Davidovitch, N. (2016). Leisure in the $21^{\text {st }}$ century: Tradition and modernity. Gadish, 16, 207-217. [Hebrew]

Davidovitch, N., \& Roman Y. (2018). The Impact of Mobile Tablet Use on Students 'perception of Learning Processes. Problems of Education in the 21st Century 76.1

Fischer, C. M., Wartick, M., \& Mark, M. (1992). Detection probability and taxpayer compliance: A review of the literature. Journal of Accounting Literature, 11, 1-46.

Hartz Soraker, J. (2012). How shall I compare thee? Comparing the prudential value of actual and virtual friendship. Ethics and Information Technology, 14(3), 209-219. https://doi.org/10.1007/s10676-012-9294-x

Heiman, T., Olenik-Shemesh, D., \& Eden, S. (2014). Special issue: Learning disabilities (LD) and attention deficit disorder (ADD): Theory, research, and policy (pp. 93-112). Mifgash: Journal of Social-Educational Work, 39 [Hebrew]. 
Hochdorf, Z. (1989). Prevention of suicidal behavior for high school students. Thesis, School of Education, University of Haifa.

Hu, M. (2009). Will online chat help alleviate mood loneliness? Cyber Psychology \& Behavior, 12(2), 219-223. https://doi.org/10.1089/cpb.2008.0134

Kim, J. H., Larose, R., \& Peng, W. (2009). Loneliness as the cause and the effect of problematic internet use: The relationship between internet use and psychological well-being. Cyber Psychology \& Behaviour, 12(4), 451-455. https://doi.org/10.1089/cpb.2008.0327

Kim, Y., Kim, E. Y., \& Kang, J. (2003). Teens' mall shopping motivation: Functions of loneliness and media usage. Family and Consumer Sciences Research, 32, 140. https://doi.org/10.1177/1077727X03032002004

Kol, O., \& Lev-On, A. (2014). Online social networks and purchase decision making. Jerusalem: Ministry of Economy. [Hebrew]

Kraut, R., Kiesler, S., Boneva, B., Cummings, J., Helgeson, V., \& Crawford, A. (2002). Internet paradox revisited. Journal of Social Issues, 58(1), 49-74. https://doi.org/10.1111/1540-4560.00248

Kraut, R., Patterson, M., Lundmark, V., Kiesler, S., Mukophadhyay, T., \& Scherlis, W. (1998). Internet paradox: A social technology that reduces social involvement and psychological well-being? American Psychologist, 53(9), 1017. https://doi.org/10.1037//0003-066X.53.9.1017

Liao, H. Y., Chen, K. Y., \& Liu, D. R. (2015). Virtual friend recommendations in virtual worlds. Decision Support Systems, 69, 59-69. https://doi.org/10.1016/j.dss.2014.11.005

Liu, X., Liu, X., \& Wei, R. (2014). Maintaining social connectedness in a fast-changing world: Examining the effects of mobile phone uses on loneliness among teens in Tibet. Mobile Media \& Communication, 2(3), 318-334. https://doi.org/10.1177/2050157914535390

Neudörfer, P., \& Dresdner, J. (2013). Does religious affiliation affect migration? Papers in Regional Science. https://doi.org/10.1111/pirs.12016

Nowland, R., Necka, E., \& Cacioppo, J. (2017). Loneliness and social internet use: Pathways to reconnection in a digital world? Perspectives on Psychological Science, 13(1), 70-87. https://doi.org/10.1177/1745691617713052

Papadakis, S. (2016). Creativity and innovation in European education. 10 years eTwinning. Past, present and the future. International Journal of Technology Enhanced Learning, 8(3/4), 279-296. https://doi.org/10.1504/IJTEL.2016.082315

Peplau, L. A., Russell, D., \& Heim, M. (1979). The experience of loneliness. In I. H. Frieze, D. Bar-Tal, \& J. S. Carroll (Eds.), New approaches to social problems: Applications of attribution theory (pp. 53-78). San Francisco: Jossey-Bass.

Perlman, D., \& Peplau, L. A. (1981). Toward a social psychology of loneliness. In R. Gilmour \& S. Duck (Eds.), Personal Relationships: 3. Relationships in Disorder (pp. 31-56). London: Academic Press.

Peter, J., Valkenburg, P. M., \& Fluckiger, C. (2009).Adolescents and social network sites: Identity, friendships and privacy. In S. Livingstone \& L. Haddon (Eds.), Kids online (pp. 83-94). Bristol, UK: Policy Press. https://doi.org/10.1332/policypress/9781847424396.003.0007

Rasner, N., \& Zeira, A. (2014). Adolescent girls in severe situations of distress. Haruv Institute. [Hebrew]

Resler, Y. (1998). The effect of innovative technologies on thinking. Talelei Orot, 8, 390-403. [Hebrew]

Ronen, M., Zuckerman-Bareli, H., \& Lemel, S. (1990). Variables affecting isolation of elderly people. Israel Gerontological Society, 47/48, 26-41. [Hebrew]

Rosenberg, H. (2015). Media, children, and teens: Data on consumption, use habits, and social practices. Chapter 7, in R. Mann \& A. Lev-On (Eds.), The annual report: Media in Israel 2015: Agenda, usages, and trends. The Institute for the Study of New Media, Politics and Society, with the Yifat Group and TGI Single Source Ltd. http://aunmedia.org/sites/default/files/research/mr2015/MediaReport2015\%20Ch7.pdf [Hebrew]

Russell, D., Peplau, L. A., \& Cutrona, C. E. (1980). The revised UCLA Loneliness Scale: Concurrent and discriminant validity evidence. Journal of Personality and Social Psychology, 39(3), 472. https://doi.org/10.1037/0022-3514.39.3.472

Sharabi, A., \& Malka, M. (2011). Virtual friendships and social distress among adolescents with and without learning disabilities: The subtyping approach. European Journal of Special Needs Education, 26(3), 379-394. https://doi.org/10.1080/08856257.2011.595173 
Sharabi, A. (2013). Social ties on the internet and sense of loneliness among students with and without learning disabilities. CET (Center for Educational Technology) Website http://itu.staging.cet.ac.il/FileViewer.aspx?nFileID=17426 [Hebrew]

Twenge, J. M. (2017). Have smartphones destroyed a generation. The Atlantic, 3.

Twenge, J. M., Joiner, T. E., Rogers, M. L., \& Martin, G. N. (2018). Increases in depressive symptoms, suicide-related outcomes, and suicide rates among US adolescents after 2010 and links to increased new media screen time. Clinical Psychological Science, 6(1), 3-17. https://doi.org/10.1177/2167702617723376

Weissblei, E. (2011). Children in social networks on the internet. Knesset Research and-Information-Center. https://www.knesset.gov.il/mmm/data/pdf/m02856.pdf [Hebrew]

Zahavi-Suzy, S. (2012). Development is at a rate previously unknown by the human race. Café Magazine. [Hebrew]

\section{Appendix A - Virtual friendship questionnaire on excessive use of social networks}

Part I

1. On which social networks are you active? Twitter, Facebook, Snapchat, Instagram, WhatsApp, any other social network on which you are active (please mark all relevant answers).

2. What is your preferred social network? Twitter, Facebook, Snapchat, Instagram, WhatsApp, any other social network on which you are active (please mark all relevant answers).

3. For how long have you been active on social networks? About one year / up to two years / 3-4 years / 5-6 years / more than 7 years.

4. To what degree do you speak with friends from school or from your residential area on social networks? Not at all / a little / moderately / a lot / very much.

5. To what degree do you speak with friends that you met only on social networks? Not at all / a little / moderately / a lot / very much.

6. How important and significant is this relationship for you? Not at all / a little / moderately / a lot / very much. 


\section{Part II}

Please mark how often you feel as described in each of the following statements (if you are answering on a mobile phone, please rotate the screen):

\begin{tabular}{|c|c|c|c|c|c|}
\hline & $\begin{array}{l}\text { Strongly } \\
\text { disagree }\end{array}$ & $\begin{array}{l}\text { Slightly } \\
\text { disagree }\end{array}$ & $\begin{array}{l}\text { Moderately } \\
\text { agree }\end{array}$ & Agree & $\begin{array}{l}\text { Strongly } \\
\text { agree }\end{array}$ \\
\hline I remain on the social network more than I had planned to. & & & & & \\
\hline $\begin{array}{l}\text { 2. I neglect housework / homework / work and instead spend more time } \\
\text { on the internet. }\end{array}$ & & & & & \\
\hline $\begin{array}{l}\text { 3. I can free time spent on social networks in order to spend time with my } \\
\text { family. }\end{array}$ & & & & & \\
\hline $\begin{array}{l}\text { 4. I can't stop myself from accessing the social networks, even though I } \\
\text { understand that long hours of access are bad for my health. }\end{array}$ & & & & & \\
\hline 5. People complain about the amount of time I spend on the internet. & & & & & \\
\hline 6. I check my account on the social networks before I do my assignments. & & & & & \\
\hline 7. My performance is impaired due to the time spent on social networks. & & & & & \\
\hline $\begin{array}{l}\text { 8. I become defensive or secretive when asked what I am doing on the } \\
\text { internet. }\end{array}$ & & & & & \\
\hline 9. I argue aggressively with people who object to social networks. & & & & & \\
\hline $\begin{array}{l}\text { 10. I can't stop myself from entering social networks where it is forbidden } \\
\text { (such as work / class etc.) even knowing that when I am caught it will } \\
\text { have grave implications }\end{array}$ & & & & & \\
\hline $\begin{array}{l}\text { 11. I am afraid that life without social networks will be boring, empty, and } \\
\text { unenjoyable }\end{array}$ & & & & & \\
\hline $\begin{array}{l}\text { 12. I become aggressive, loud, or irritable if someone disturbs me while I } \\
\text { am on social networks. }\end{array}$ & & & & & \\
\hline 13. My sleep time is gradually diminishing due to late night entrances. & & & & & \\
\hline 14. I try to reduce my time on social networks but I fail. & & & & & \\
\hline $\begin{array}{l}\text { 15. I try to conceal from my family the amount of time that I am on social } \\
\text { networks. }\end{array}$ & & & & & \\
\hline $\begin{array}{l}\text { 16. I choose to spend more time on social networks over going out with } \\
\text { friends. }\end{array}$ & & & & & \\
\hline $\begin{array}{l}\text { 17. I feel depressed, under the weather, or nervous when I'm not on social } \\
\text { networks, and this sensation disappears when I connect once again. }\end{array}$ & & & & & \\
\hline $\begin{array}{l}\text { 18. If I choose not to connect to social networks, I might feel depressed or } \\
\text { insignificant. }\end{array}$ & & & & & \\
\hline 19. I feel guilt when I "text" during class / driving / work. & & & & & \\
\hline 20. I can’t go an entire day without being on social networks. & & & & & \\
\hline $\begin{array}{l}\text { 21. I intentionally respond positively to posts by others in order to avoid } \\
\text { unnecessary conflicts. }\end{array}$ & & & & & \\
\hline $\begin{array}{l}\text { 22. It is hard for me when I understand that others have more friends on } \\
\text { social networks than I do. }\end{array}$ & & & & & \\
\hline 23. I hate negative responses to my posts. & & & & & \\
\hline 24. I truly like all the people who are my friends on social networks. & & & & & \\
\hline 25. I feel comfortable exposing myself on social networks. & & & & & \\
\hline 26. Receiving information about others' activities gives me pleasure. & & & & & \\
\hline $\begin{array}{l}\text { 27. I am active on social networks because everyone else is, and if I would } \\
\text { not be active then I would be considered old-fashioned. }\end{array}$ & & & & & \\
\hline $\begin{array}{l}\text { 28. I have put a lot of effort into maintaining relationships formed on the } \\
\text { social networks. }\end{array}$ & & & & & \\
\hline $\begin{array}{l}\text { 29. If I receive no responses to my posts, my desire to write again next time } \\
\text { diminishes. }\end{array}$ & & & & & \\
\hline $\begin{array}{l}\text { 30. If I receive lots of negative responses then I am discouraged and don't } \\
\text { write anything similar. }\end{array}$ & & & & & \\
\hline $\begin{array}{l}\text { 31. I make sure to give a positive response, even fake, to someone who } \\
\text { responded positively to me in the past, thus ensuring future positive } \\
\text { responses. }\end{array}$ & & & & & \\
\hline 32. Online relationships are of better quality than face-to-face relationships. & & & & & \\
\hline $\begin{array}{l}\text { 33. Social networks help me leave behind the daily frustration and } \\
\text { disappointment. }\end{array}$ & & & & & \\
\hline $\begin{array}{l}\text { 34. After being connected and active on social networks, I feel that my } \\
\text { social needs have been met and satisfied. }\end{array}$ & & & & & \\
\hline $\begin{array}{l}\text { 35. I strongly wish to post my latest pictures or update my status on social } \\
\text { networks. }\end{array}$ & & & & & \\
\hline 36. I always receive true responses from others. & & & & & \\
\hline 37. I like to share my daily activities with others. & & & & & \\
\hline 38. I am glad to receive a positive response. & & & & & \\
\hline $\begin{array}{l}\text { 39. The smaller the discrepancy between my posts on social networks and } \\
\text { the positive responses, the better I feel. }\end{array}$ & & & & & \\
\hline 40. I speak to my friends on the internet more than face-to-face. & & & & & \\
\hline
\end{tabular}


Appendix B - The Revised UCLA Loneliness Scale

\begin{tabular}{l|l|l|l|l|l}
\hline & & Often & Sometimes & Rarely & Never \\
\hline 12. & I think the same as the people around me & 4 & 3 & 2 & 1 \\
\hline 13. & I lack friends & 4 & 3 & 2 & 1 \\
\hline 14. & I have no one to turn to & 4 & 3 & 2 & 1 \\
\hline 15. & I feel lonely & 4 & 3 & 2 & 1 \\
\hline 16. & I feel that I belong to a group of people & 4 & 3 & 2 & 1 \\
\hline 17. & I have lots of things in common with my friends & 4 & 3 & 2 & 1 \\
\hline 18. & I'm no longer close to anyone & 4 & 3 & 2 & 1 \\
\hline 19. & My interests and occupations do not interest anyone & 4 & 3 & 2 & 1 \\
\hline 20. & I am an open person & 4 & 3 & 2 & 1 \\
\hline 21. & There are people to whom I feel close & 4 & 3 & 2 & 1 \\
\hline 22. & I feel "out of things" & 4 & 3 & 2 & 1 \\
\hline 23. & My social ties are superficial & 4 & 3 & 2 & 1 \\
\hline 24. & No one knows me well & 4 & 3 & 2 & 1 \\
\hline 25. & I feel isolated & 4 & 3 & 2 & 1 \\
\hline 26. & I can find friends when I want to & 4 & 3 & 2 & 1 \\
\hline 27. & Some people truly understand me & 4 & 3 & 2 & 1 \\
\hline 28. & I am miserable because I'm so isolated from friends & 4 & 3 & 2 & 1 \\
\hline 29. & There are people around me but not with me & 4 & 3 & 2 & 1 \\
\hline 30. & There are people with whom I can talk & 4 & 3 & 2 & 1 \\
\hline 31. & There are people to whom I can turn & 4 & 3 & 2 & 1 \\
\hline
\end{tabular}

\section{Appendix C - Instructions for completing the questionnaires}

Dear participant,

Thank you for participating in the study. The study is on the nature friendship in the technological era. In the study, you will be asked to complete several questions. The study takes about 10 minutes. The study is anonymous and all the data that will be collected are only for the purposes of the study. Your participation in the study is voluntary. You can stop your participation in the study at any time, with no implications for you. Please confirm that you have understood the information above and that you consent to participate in the study.

I confirm that I have understood the information above and that I agree to participate in the study.

In addition, if you are answering on a mobile phone, please turn the screen horizontally to see all the options.

Thank you very much!

\section{Copyrights}

Copyright for this article is retained by the author(s), with first publication rights granted to the journal.

This is an open-access article distributed under the terms and conditions of the Creative Commons Attribution license which permits unrestricted use, distribution, and reproduction in any medium, provided the original work is properly cited. 